\title{
Caso Ramírez Escobar $Y$ Otros vs. Guatemala: Um Novo Olhar Da Corte Interamericana De Direitos Humanos Sobre A Corrupção
}

\section{Flávio Pereira da Costa Matias*}

Universidade Católica de Brasília, Programa de Pós-Graduação em Direito da UCB, Brasília, Distrito Federal, Brasil.

\section{ORCID https://orcid.org/0000-0002-1645-8193}

\section{Julio Cesar de Aguiar**}

Universidade Católica de Brasília, Programa de Pós-Graduação em Direito da UCB, Brasília, Distrito Federal, Brasil.

\section{ORCID https://orcid.org/00oo-0002-8252-2894}

Resumo: Este artigo tem como objetivo discutir o novo olhar da Corte Interamericana de Direitos Humanos a partir da relação entre direitos humanos e corrupção. Inicia-se pela construção histórica dos direitos humanos para examinar se a corrupção pode ser considerada uma forma de violação de tais direitos e, em caso afirmativo, sob quais hipóteses. Demonstra-se a maneira pela qual o direito internacional enfrenta a corrupção, tanto regional como globalmente, normalmente sob a perspectiva da luta contra a corrupção. É dada especial atenção ao tratamento que a Organização das Nações Unidas concedeu à redução da corrupção no âmbito dos Objetivos de Desenvolvimento Sustentável dentro da Agenda 2030 e à recente decisão proferida pela Corte Interamericana de Direitos Humanos no caso Ramírez Escobar y Otros Vs. Guatemala, no qual ela abordou expressamente a relação entre corrupção e violações de direitos humanos, e reafirma-se a necessidade de se encarar a corrupção como uma forma de violação de direitos humanos. O método utilizado para o artigo foi a pesquisa bibliográfica, de natureza exploratória, utilizando textos de direitos humanos diversos e tratados internacionais, e a pesquisa jurisprudencial da Corte Interamericana de Direitos Humanos.

Palavras-chave: Corrupção. Direitos Humanos. Corte Interamericana de Direitos Humanos.

\footnotetext{
* Mestrando em Direito pela Universidade Católica de Brasília.

E-mail: flaviopcmatias@gmail.com

** Professor do programa de Pós-Graduação em Direito da Universidade Católica de Brasília.
E-mail: juliocesar.deaguiar@gmail.com
}

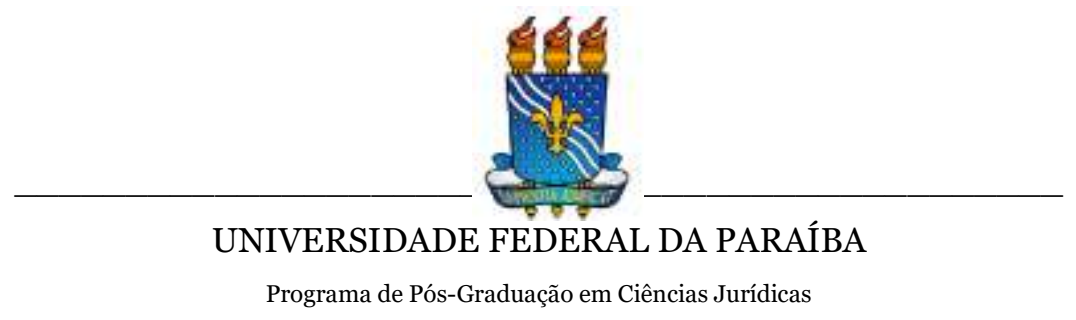

DOI: https://doi.org/10.22478/ufpb.1678-2593.2020v19n41.44744 


\title{
Caso Ramírez Escobar Y Otros vs. Guatemala: Um Novo Olhar Da Corte Interamericana De Direitos Humanos Sobre A Corrupção
}

\author{
Flávio Pereira da Costa Matias
}

Julio Cesar de Aguiar

\section{INTRODUÇÃO}

A corrupção, os danos por ela causados em nível local e global e as formas de enfrentá-la são cada vez mais objeto de intensa reflexão e discussão. Diariamente a imprensa nacional e internacional noticia casos de corrupção em que se envolvem autoridades públicas e grandes empresas, muitas vezes dando destaque à soma desviada do erário, ou de sociedades empresariais, para particulares.

No Brasil, conquanto o fenômeno da corrupção sempre tenha estado presente no debate político e relacionado à administração pública, é inegável que a partir dos casos Mensalão ${ }^{1}$ e especialmente Lava Jato $^{2}$ ela ascendeu a uma posição de primazia, ao ponto de ser

\footnotetext{
1 "Mensalão" é como ficou conhecida na imprensa a Ação Penal 470, que tramitou no Supremo Tribunal Federal e condenou por crimes diversos parte da cúpula do Partido dos Trabalhadores (PT), à frente do Poder Executivo federal de 2003 a 2016. A alcunha "Mensalão" é atribuída a Roberto Jefferson, ex-deputado federal pelo Rio de Janeiro e ex-presidente do Partido Trabalhista Brasileiro, um dos pivôs do escândalo.

${ }^{2}$ No início, uma investigação contra doleiros que agiam no Paraná, a operação Lava Jato já resultou, apenas nesse estado, na prisão e acusação formal de trezentas e quarenta e sete pessoas (dados atualizados até 15 de outubro de 2018, vide http://www.mpf.mp.br/para-o-cidadao/caso-lava-jato/atuacao-na-1ainstancia/atuacao-na-1a-instancia/parana/resultado), dentre figuras de prestígio nos meios político e empresarial, estendendo-se também para os estados do Rio de
} 
apontada por pesquisa de 2015 do instituto Datafolha como o maior problema do país (MENDONÇA, 2015).

Em 2017, foi a vez da pesquisa de opinião pública Latinobarômetro, de forma inédita ao longo dos seus vinte e dois anos de existência, registrar a corrupção como a principal preocupação de um país dentre os dezoito pesquisados (FIGUEIREDO, 2017), e esse país foi justamente o Brasil. A coordenadora do Latinobarômetro e pesquisadora chilena Marta Lagos declarou, em entrevista ao jornal O Globo, que cerca de $97 \%$ dos brasileiros "acreditam que o governo não governa para eles e sim pensando em outros interesses, que nada têm a ver com as demandas da sociedade" (FIGUEIREDO, 2017).

A importância da corrupção como problema nacional pode ser inferida também das eleições de 2018, quando acusações recíprocas entre candidatos e agremiações partidárias em torno da corrupção, "caixa dois" e outras ilegalidades ditaram o rumo dos debates, sendo perceptível que candidatos que lograram associar a respectiva imagem à de incorruptível ou de outsider obtiveram resultados surpreendentes, como se deu na eleição para governador de Minas Gerais e Rio de Janeiro, para ficar com apenas dois exemplos3.

Tentativas de movimentar o xadrez legislativo para estabelecer novas formas de combate à corrupção, contudo, são geralmente vistas como manifestações de punitivismo ou de um estado policial antidemocrático, algo ofensivo aos direitos humanos. Desenha-se um cenário em que combate à corrupção e direitos humanos contrapõe-se diametralmente, e o debate sobre novas formas de se lutar contra a corrupção é permeado de objeções à mudança do status quo legislativo (IBCCRIM, 2015, p. 01), a exemplo do pacote das 10 Medidas Contra a Corrupção, rejeitado por ampla maioria na

Janeiro e São Paulo, dentre outros, além do Distrito Federal, bem como para outros países latino-americanos, onde empresas brasileiras se envolveram em crimes diversos.

3 Posto que não seja objeto deste artigo, convém deixar registrado que atrelar a corrupção a um partido político ou ideologia específicos não possui nenhum respaldo na literatura especializada nem na experiência histórica. Ao contrário, a literatura é razoavelmente pacífica em sustentar o caráter apartidário da corrupção. 
Câmara dos Deputados em novembro de 2016, ao ponto de o relator do Projeto de Lei 4.850 - que tratava da matéria - ter dito que, do jeito que as coisas estavam se encaminhando, sobraria "meia medida" (BRAGON, 2016).

É nesse contexto que se mostra oportuno investigar se essa suposta contraposição entre direitos humanos e enfrentamento à corrupção é procedente, ou se, ao revés, a promoção dos direitos humanos é indissociável do combate à corrupção. $\mathrm{O}$ objetivo deste estudo, nessa linha, é demonstrar que, a partir do tratamento internacional dado ao enfrentamento à corrupção, coroado por recente decisão da Corte Interamericana de Direitos Humanos, esse suposto antagonismo não deve mais subsistir.

Para isso, será traçada o caminho da construção dos direitos humanos ao longo da história, ressaltando a dinamicidade do conceito e sua origem histórica. Em seguida, abordar-se-ão os impactos que a corrupção acarreta nos direitos humanos, particularmente no Brasil.

Em seguida, será enfocado o panaroma internacional do enfrentamento à corrupção, com destaque para as normas internacionais que fomentam a responsabilização dos atos corruptos e para o tratamento dado pela Organização das Nações Unidas, especialmente os Objetivos do Desenvolvimento Sustentável.

Por fim, examinar-se-á o caso Ramírez Escobar y Otros Vs. Guatemala, julgado em 2018 pela Corte Interamericana de Direitos Humanos, o qual pode servir como ponto de inflexão para a superação da suposta incompatibilidade entre o combate à corrupção e a proteção dos direitos humanos.

\section{A CONSTRUÇÃO HISTÓRICA DOS DIREITOS HUMANOS}

A noção de direitos humanos foi antecedida, na Antiguidade, pela concepção de um direito superior, não estabelecido pelos homens, 
mas dado pelos deuses (FERREIRA FILHO, 2011, p. 27), a qual é bem ilustrada pela passagem da peça Antígona em que a protagonista, desobedecendo ao edito de seu tio Creonte, tenta enterrar seu irmão Polinices e, ao ser flagrada e levada ao rei Creonte, diz-lhe que a norma por ela descumprida não tinha força para impor a obrigação de transgredir normas divinas, não escritas, inevitáveis (SÓFOCLES, 2002, p. 219).

Comparato (2005, p. 20) leciona que foi sobre a concepção medieval de pessoa, trabalhada por Boécio no Século VI e integralmente adotada por Tomás de Aquino no século XIII, que se iniciou a elaboração do princípio da igualdade essencial de todo o ser humano, não obstante todas as diferenças individuais ou grupais, de ordem biológica ou cultural, e é essa igualdade de essência das pessoas que forma o núcleo do conceito universal de direitos humanos, comuns a toda a espécie humana.

O primeiro registro histórico dos direitos humanos tal como os conhecemos atualmente, entretanto, veio a lume com a Seção I da Declaração de Direitos da Virgínia (COMPARATO, 2005, p. 49), de 1776, que assim dispõe (NATIONAL ARCHIVES, 2016):

Todos os homens são por natureza igualmente livres e independentes e têm alguns direitos ínsitos, dos quais, quando adentram o estado de sociedade, eles não podem, por nenhum acordo, despir ou privar sua posteridade, especificamente o gozo da vida e da liberdade, com os meios de adquirir e possuir propriedades, e buscar e obter felicidade e segurança.4 (tradução nossa)

Anos após, em 1789, seria a vez de a Declaração dos Direitos do Homem e do Cidadão, com seus dezessete artigos, ser promulgada no curso da Revolução Francesa e estabelecer vários direitos humanos, como o direito à igualdade perante a lei, a liberdade de opinião, a

\footnotetext{
4 "That all men are by nature equally free and independent and have certain inherent rights, of which, when they enter into a state of society, they cannot, by any compact, deprive or divest their posterity; namely, the enjoyment of life and liberty, with the means of acquiring and possessing property, and pursuing and obtaining happiness and safety."
} 
anterioridade da lei penal, dentre outros. O caráter inovador e abrangente da Declaração de 1789 certamente contribuiu para que ela estivesse em vigor na França até o momento, onde goza de status constitucional $5 \mathrm{e}$, por isso, serve de parâmetro ao exercício do controle de constitucionalidade.

Avançando na recente internacionalização dos direitos humanos, na segunda metade do Século XX, o holocausto e as tragédias acontecidas na Segunda Guerra Mundial levaram ao surgimento da Organização das Nações Unidas (ONU) - em substituição à fracassada Liga das Nações -, no seio da qual foi elaborada a Declaração Universal dos Direitos Humanos, proclamada pela Assembleia Geral da ONU em Paris, em 10 de dezembro de 1948. Posteriormente, em 1966, a Assembleia Geral da ONU adotou dois tratados internacionais, o Pacto Internacional de Direitos Civis e Políticos (PIDCP) e o Pacto Internacional dos Direitos Econômicos, Sociais e Culturais (PIDESC), com força de jus cogens, isto é, obrigatórios e inalteráveis pela vontade unilateral de um só Estado (RAMOS, 2012b, p. 125).

O marco histórico em que consistiu a Declaração de Direitos da Virgínia, entrementes, não desconstrói o fato de que "os direitos não surgiram todos ao mesmo tempo, nem foram resultados de um big bang jurídico que esteja a impedir a vista de alcançar o que havia antes da grande explosão" (SAMPAIO, 2010, p. 133-134). Documentos como a Virgina Declaration of Rights, e mesmo a Declaração Universal dos Direitos Humanos, têm sua importância enquanto referência histórica dentro de um discurso sobre direitos humanos que, sem esses momentos, ficaria solto e sem sentido (BIELEFELDT, 2000, p. 102).

Nessa mesma linha, segundo a qual os direitos não nascem todos de uma vez, mas nascem quando devem ou podem nascer, Bobbio (2004, p. 6 e 18) ressalta o caráter histórico dos direitos humanos para afirmar que não existem direitos fundamentais por

5 É o que se vê do sítio eletrônico do governo francês, disponível em: https://www.legifrance.gouv.fr/Droit-francais/Constitution, bem como de decisões do Conselho Constitucional. 
natureza, pois o que parece fundamental numa época histórica e numa determinada civilização não é fundamental em outras épocas e em outras culturas.

Disso resulta que, para além da dicotomia entre direitos humanos e fundamentais - a primeira expressão gozando da preferência dos autores anglo-americanos e latinos, a segunda, dos publicistas alemães, segundo Bonavides (2010, p. 560) - e das gerações ou dimensões de direitos fundamentais (BONAVIDES, 2010, p. 571-572), é crucial atentar para o caráter dinâmico e moldável que os direitos adquirem ao longo da história. Por isso, é possível afirmar junto a Bielefeldt (2000, p. 109) que:

A luta pelos direitos não é apenas uma luta pela concretização de postulados que se fixem para sempre, mas também uma discussão sobre o conteúdo e alvo de reivindicações jurídicas concretas, que se alteraram substancialmente no decorrer dos últimos duzentos anos e que, certamente, ainda muito se alterarão no futuro.

Esse caráter dinâmico do conteúdo dos direitos humanos propiciou um debate em torno de um direito a uma sociedade livre de corrupção como um direito humano básico, fundamental, porquanto os direitos à vida, à dignidade e outros valores humanos cruciais dependeriam dele (KOKELE-KALE, 2000, p. 163). Isso porque, particularmente em relação a grandes esquemas de corrupção em países em desenvolvimento, o ato corrupto representa graves prejuízos para a população e sua riqueza (PIMENTEL FILHO, 2015, p. 110).

É nesse contexto de reconstrução histórica gradativa do conceito de direitos humanos que a relação entre tais direitos - e a correlata violação - e a corrupção deve ser abordada, perscrutando se a corrupção pode efetivamente ser encarada como uma violação dos direitos humanos. 


\section{A CORRUPÇÃO NO BRASIL E SEU IMPACTO NOS DIREITOS HUMANOS}

Conquanto seja uma palavra polissêmica, a corrupção pode ser conceituada, acolhendo a lição da organização não governamental Transparência Internacional (2018, p. 04), como o abuso de poder confiado a alguém para obtenção de ganhos privados. Trata-se de significado bastante distinto daquele empregado no direito penal, que concerne especificamente aos crimes de corrupção passiva ou ativa e que não que nos interessa para os fins deste artigo.

A definição da Transparência Internacional de corrupção, obviamente, não é isenta de críticas, mas num panorama em que até a Convenção das Nações Unidades Contra a Corrupção, conhecida como Convenção de Mérida, se exime em conceituar corrupção justamente pela falta de concordância em torno de uma definição precisa (HOLMES, p. 02), é admissível justamente por não ser excludente indo bastante além da definição costumeira do direito penal - e focar no essencial: a quebra de confiança e o ganho indevido em detrimento de outros. Nessa mesma linha de compreensão, Guimarães (2012, p. 147) sustenta que “a corrupção pode ser definida como ato de transgressão do interesse público, que implica uma apropriação privatista ilegítima de recursos, bens, patrimônios ou serviços públicos”.

A corrupção faz parte do dia a dia dos brasileiros, se não diretamente em razão do sofrimento dos abusos por ela causados, isto é, como vítimas de agentes corruptos, ao menos como vítima indireta do estrago que a corrupção faz num país que é a oitava maior economia do mundo, mas joga $55 \%$ do seu esgoto na natureza sem tratamento adequado (INSTITUTO TRATA BRASIL, 2018, p. 59). A Federação das Indústrias do Estado de São Paulo, em estudo de 2017, estimou o custo anual da corrupção para o Estado brasileiro em cerca de R $\$ 130$ 
bilhões, cerca de $2 \%$ do Produto Interno Bruto, quantia essa que organizações não governamentais que atuam na matéria consideram estar subestimada (SOARES, 2017).

A relação entre corrupção e as implicações na violação de direitos humanos, sem embargo, é variada. Há casos em que a corrupção pode levar a violações de direitos humanos, porém ela não corresponde a uma violação direta a tais direitos (BACIOTERRACINO, 2008. p. 8). É o caso da difundida "taxa de urgência", em que o cidadão paga propina a um agente público para ter um andamento mais rápido em alguma solicitação administrativa (a emissão de uma carteira de motorista, por exemplo). Resta, de toda forma, a quebra de confiança no Estado, devido à extorsão a que o cidadão é submetido, o que remete aos resultados das pesquisas aludidas na introdução deste texto.

Já em outras hipóteses, é flagrante a violação de direitos humanos na prática corrupta. É o que ocorre amplamente no Brasil, onde cerca de $67 \%$ dos casos de desvio de recursos federais repassados a estados e municípios ocorrem nas áreas da saúde e educação (SOUZA, 2016).

Da mesma forma, e para ficar com apenas um exemplo concreto dentre centenas, na Operação Protheus, deflagrada no Mato Grosso no ano de 2015 no curso de investigação sobre a malversação de recursos públicos destinados ao saneamento básico em diversos municípios daquele estado, o desvio de cerca de $\mathrm{R} \$ 30$ milhões atingiu o abastecimento de água e o tratamento do esgoto de cerca de oitocentas mil pessoas (ANJOS, 2015).

Em rigor, podemos afirmar com Pimentel Filho (2015, p. 87) que a corrupção pode afetar direta e casuisticamente qualquer direito, seja o direito à propriedade - quando um fiscal extorque um contribuinte para que lhe transfira um imóvel de propriedade desse a fim de que assim não seja lavrado um auto de infração milionário, por exemplo -, o direito à reunião - comandante de polícia que proíbe o exercício pacífico do direito de reunião, a menos que lhe paguem 
propina -, a liberdade de expressão - jornal que é censurado por não contribuir financeiramente com o partido político que está no poder etc.

Contudo, é inegável que da estreita intimidade entre corrupção e prejuízo a políticas públicas decorre o fato que os direitos aos quais Bobbio (2004, p. 05) e Bonavides (2010, p. 571-572) denominam direitos de segunda geração - aqueles de natureza prestacional, como os direitos sociais e econômicos - e de terceira geração - que possuem natureza difusa, como o direito ao meio ambiente ecologicamente equilibrado e os direitos dos consumidores - sofrem mais diretamente os impactos nefastos da corrupção, na medida em que tais categorias de direitos humanos exigem uma atuação estatal mais ativa por meio de atuações positivas em promover e executar políticas públicas ou em proteger proativamente interesses que dizem respeito a toda sociedade, de natureza difusa. Tampouco pode ser subestimada a quantia de dinheiro desviada dos cofres públicos e a gravosa consequência nas políticas públicas a que ela se destinava, como bem demonstram as abundantes quantidades de creches, escolas, hospitais e outras obras inacabadas devido ao sumiço dos recursos que lhes custeariam. Auditoria do Tribunal de Contas da União em 2019 apurou que 37,5\% das obras custeadas com recursos da União estavam paralisadas ou inacabadas (TCU, 2019).

É imperativo, de toda sorte, pontuar que a luta contra a corrupção não é um fim em si mesmo, tampouco resolverá todos os obstáculos ao desenvolvimento e bem-estar de uma dada nação. Reduzir a corrupção, com efeito, é um só dos muitos objetivos que deve ter uma autoridade pública, um político ou um legislador (KLITGAARD, 1994, p. 43). São as políticas públicas estabelecidas democraticamente que hão de guiar o rumo das nações. O problema é que qualquer política pública é irrelevante num ambiente onde a corrupção é a norma e onde altos preços são pagos por quem denuncia práticas corruptas, não pelos corruptos (MUNGIU-PIPPIDI, p. xii).

A corrupção, portanto, se mostra como um entrave ao atendimento dos objetivos democraticamente perseguidos pelas 
Caso Ramírez Escobar Y Otros vs. Guatemala: Um Novo Olhar Da Corte...

sociedades contemporâneas, além de uma forma de violação de direitos humanos. Ela possui custos de eficiência em função do desperdício e da má distribuição que em geral a acompanham (KLITGAARD, 1994, p. 56), do que é exemplo do nosso cotidiano o superfaturamento de obras. Para ficar com um exemplo, em apenas dez obras executadas pela empresa Odebrecht no Rio de Janeiro, o superfaturamento de obras identificado pelos Tribunais de Conta do Estado e da União superou 3,1 bilhões de reais, e o total de atrasos somam trinta e cinco anos (GRANDIN, 2017).

Reduzir drasticamente a corrupção, portanto, é uma medida que se impõe para que as políticas públicas necessárias para a implementação dos direitos humanos possam apresentar os resultados que delas se esperam. Um olhar sobre o que vem sendo feito no âmbito internacional contra a corrupção, nessa linha, revela-se importante para que possamos verificar qual o tratamento que lhe é concedido.

\section{O PANORAMA INTERNACIONAL DO ENFRENTAMENTO À CORRUPÇÃO}

Na presente seção, serão analisadas primeiramente as normas internacionais que tratam da corrupção com enfoque na responsabilização. Em seguida, examinar-se-ão alguns casos em que a corrupção é objeto de normas e entidades internacionais de direitos humanos.

\subsection{O panorama internacional da responsabilização da corrupção}

Em 1977, foi aprovado nos Estados Unidos da América o U.S. 
Foreign Corrupt Practices Act (FCPA), na sequência do escândalo, em que se constatou que empresas norte-americanas estavam pagando propina no estrangeiro de forma difundida (PALIFKA; ROSEACKERMAN, 2016, p. 463). O FCPA é considerado na literatura como o primeiro passo importante no enfrentamento da corrupção comercial transnacional (VERÍSSIMO, 2017, p. 150) e proibiu que empresas americanas usassem do pagamento de propinas para obter negócios no exterior (PIMENTEL FILHO, 2015, p. 123).

A partir dos anos 1990, com o fim da Guerra Fria, instituições internacionais, como o Banco Mundial, começaram a promover uma agenda anticorrupção mundo afora (PALIFKA; ROSE-ACKERMAN, 2016, p. 446). Igualmente, o Fundo Monetário Internacional passou a exigir a implementação de medidas de governança para que os recursos oriundos dos empréstimos concedidos não fossem todos desviados para fins espúrios (PIMENTEL FILHO, 2015, p. 122).

Sob pressão dos Estados Unidos, para quem a promulgação da FCPA passou a representar uma desvantagem competitiva - na medida em que alguns países não apenas não puniam empresas envolvidas em corrupção no estrangeiro, como, a exemplo da Alemanha, ainda permitiam que tais custos fossem contabilizados para dedução de impostos (CARVALHO, 2014, p. 37) -, a Organização para a Cooperação e Desenvolvimento Econômico (OCDE), organização internacional composta por trinta e seis dos Estados economicamente mais fortes, aprovou a Convenção sobre o Combate à Corrupção de Funcionários Públicos Estrangeiros em Transações Comerciais, que foi concluída em 1997 e vigente a partir de 1999. No Brasil, essa convenção foi internalizada pelo Decreto $\mathrm{n}^{0}$ 3.678. de 2000, e deu origem à Lei ${ }^{0}{ }^{10.467}$, de 2002, que inseriu os tipos legais dos arts. 337-B A 337-D no Código Penal, criminalizando a corrupção de funcionário público estrangeiro por particular.

Um pouco antes, em 29 de março de 1996, a Organização dos Estados Americanos celebrou a Convenção Interamericana Contra a Corrupção, na cidade de Caracas, Venezuela (daí porque ela é também conhecida por Convenção de Caracas). A Convenção Interamericana 
Contra a Corrupção foi inserida no direito interno pelo Decreto $4.410 / 2002$.

No preâmbulo, a Convenção de Caracas destaca que "a corrupção solapa a legitimidade das instituições públicas e atenta contra a sociedade, a ordem moral e a justiça, bem como contra o desenvolvimento integral dos povos", e no seu artigo II estabelece ter por objetivos, dentre outros, promover e desenvolver os mecanismos necessários para prevenir, detectar, punir e erradicar a corrupção (BRASIL, 2002).

O grande tratado versando sobre a corrupção, todavia, é a Convenção das Nações Unidas Contra a Corrupção, adotada pela Assembleia Geral da ONU em 2003 e conhecida também como Convenção de Mérida, cidade mexicana onde ficou disponível para adesão em dezembro de 2003. Ela foi internalizada ao direito brasileiro por meio do Decreto 5.687, de 31 de janeiro de 2006.

A Convenção de Mérida é considerada um marco histórico no combate à corrupção, quer por englobar em um só instrumento os mais diversos aspectos concernentes ao fenômeno, possuindo normas preventivas, mandados de criminalização, medidas para a recuperação de ativos e cooperação internacional, quer pelo expressivo número de países que aderiram ao pacto (PIMENTEL FILHO, 2015, p. 126-127). Até o momento, houve cento e oitenta e seis adesões à Convenção de Mérida (UNODC, 2018).

Pode-se afirmar, com Aras (2018), existir "um regime global de proibição da corrupção, que compõem o grupo do 'bribery and corruption supression treaties', um marco normativo destinado a quatro eixos", que ele elenca como sendo a criminalização de certas condutas graves, a especificação de regras de jurisdição sobre tais crimes, a adoção de ferramentas modernas e eficientes de persecução penal criminal e de prevenção do crime e a introdução ou melhora de mecanismos de cooperação jurídica internacional.

Mais recentemente, a luta contra a corrupção tem sido temática não apenas de tratados cujo viés repressivo é predominante, 
como as três convenções aludidas linhas atrás, mas tem sido abordada pela ótica dos direitos humanos, como se verá.

\subsection{Direitos humanos e corrupção na visão das nações unidas}

Vem sendo cada vez comum na literatura fazer-se uma correlação entre os direitos humanos, fruto da luta histórica relatada linhas atrás, e a corrupção. Em igual direção caminham organismos internacionais que, se antes faziam pouca alusão aos males que a corrupção causa aos direitos humanos, passaram a posicioná-la enquanto problema de nível global merecedor de toda atenção.

Assim, o Alto Comissariado de Direitos Humanos das Nações Unidas (2006, p. 02) já consignou que a corrupção impacta os direitos humanos de vários modos, pois as consequências de se ter um governo corrupto são múltiplas e afetam a todos os direitos humanos, acrescentando (OHCHR, 2006, p.o2):

A corrupção leva à violação da obrigação do governo de tomar todas as medidas a seu alcance a fim de atingir progressivamente a completa realização dos direitos reconhecidos no Pacto Internacional de Direitos Econômicos, Sociais e Culturais. A gestão corrupta do patrimônio público compromete a habilidade do governo em entregar uma variedade de serviços, incluindo saúde, educação e serviços de bem-estar, que são essenciais para a realização dos direitos econômicos, sociais e culturais. Igualmente, a prevalência da corrupção cria uma discriminação no acesso aos serviços públicos em benefício daqueles capazes de influenciar as autoridade para agir no interesse delas, inclusive por meio de propina. ${ }^{6}$ (tradução nossa)

\footnotetext{
6 "Corruption leads to violation of the Government's obligation "to take steps... to the maximum of its available resources, with a view to achieving progressively the full realization of the rights recognized in the [International] Covenant [on Economic, Social and Cultural Rights]".i The corrupt management of public resources compromises the Government's ability to deliver an array of services, including health, educational and welfare services, which are essential for the realization of economic, social and cultural rights. Also, the prevalence of corruption creates discrimination in access to public services in favour of those able to influence the authorities to act in their personal interest, including by offering bribes. The 
O fato, como ensina com precisão Peters (2015, p. 11), é que a corrupção tanto atinge os direitos sociais previstos no Pacto Internacional de Direitos Econômicos, Sociais e Culturais - por exemplo, a corrupção na saúde pública atinge ao direito de todos ao mais alto nível possível de saúde física e mental, artigo 12,1 -, como também os direitos humanos liberais clássicos assegurados pelo Pacto Internacional de Direitos Civis e Políticos: se um preso tem que dar propina ao guarda para conseguir um cobertor ou comida de melhor qualidade, a corrupção impactará diretamente no seu direito a ser tratado dignamente na prisão e nela usufruir de condições humanas (Pacto Internacional de Direitos Civis e Políticos, artigo 10, 1).

No entanto, na prática prevalecente nas Nações Unidas, apenas expressões carentes de assertividade costumavam ser utilizadas para tratar da relação entre corrupção e direitos humanos. Segundo Peters (2015, p. 12), a quase totalidade dos textos da ONU refere-se apenas ao "impacto negativo" no gozo dos direitos humanos, ou dita que a corrupção "mina" os direitos humanos, ou enfatiza o "grave e devastador efeito da corrupção na fruição dos direitos humanos".

A despeito da ausência de assertividade no trato da corrupção, as Nações Unidas vêm nitidamente evoluindo na questão. Em agosto de 2015, a Assembleia Geral da ONU, reunida em Nova York, aprovou a Resolução 70/1, por meio da qual foi criada a Agenda 2030 para o Desenvolvimento Sustentável com a finalidade de erradicar a pobreza, proteger o planeta e garantir que as pessoas alcancem a paz e a prosperidade, a qual contém o conjunto de dezessete Objetivos do Desenvolvimento Sustentável - ODS (GENERAL ASSEMBLY, 2015, p. 01).

Dentre os dezessete Objetivos do Desenvolvimento

economically and politically disadvantaged suffer disproportionately from the consequences of corruption, because they are particularly dependent on public goods." 
Sustentável, encontra-se o Objetivo 16 "Paz, Justiça e Instituições Eficazes", voltado para o "rule of law" (ARAS, 2018), o qual se destina a "promover sociedades pacíficas e inclusivas para o desenvolvimento sustentável, proporcionar o acesso à justiça para todos e construir instituições eficazes, responsáveis e inclusivas em todos os níveis" (AGENDA 2030).

O Objetivo 16 possui um total de doze metas (GENERAL ASSEMBLY, 2015, p. 25-26), e uma dessas metas, especificamente a meta 16.5, dispõe expressamente sobre a corrupção. De acordo com a meta 16.5, consiste em um dos Objetivos do Desenvolvimento Sustentável "reduzir substancialmente a corrupção e o suborno em todas as suas formas" (GENERAL ASSEMBLY, 2015, p. 25).

Dois aspectos da meta 16.5 dos ODS são dignos de nota. O primeiro é que ela estabelece como propósito a "redução" da corrupção, e não a "eliminação" da corrupção. Isso porque, segundo a literatura especializada, o nível ótimo de corrupção não é zero. Com efeito, o combate à corrupção gera custos caros de serem pagos pela sociedade, que têm de ser sopesados com o custo da própria corrupção. Como ensina Klitgaard (1994, p. 42):

[...] Devemos considerar, em termos de custos sociais, a redução que obtemos ao diminuir os atos de corrupção, mas também precisamos levar em conta o acréscimo de custos sociais acarretado por nossos próprios esforços na luta contra ela. E isso leva à conclusão de que, na maioria dos casos, a solução de custo mínimo global não terá a corrupção igual a zero nem os esforços anticorrupção iguais ao máximo do ponto de vista de volume.

A asserção de Klitgaard é facilmente demonstrável no Brasil, onde uma estrutura burocrática amplamente disseminada impacta negativamente a atividade econômica e o dia a dia dos brasileiros sob o pretexto de prevenir corrupção e fraudes. Em pesquisa encomendada pela Fiesp e Ciesp e realizada em 2017 pelo instituto de pesquisa Ipsos, $78 \%$ dos entrevistados declararam que o excesso de burocracia dificulta o desenvolvimento do Brasil (IPSOS, 2017, p. 02). Não menos relevante foi a circunstância de que $75 \%$ dos entrevistados 
concordaram com a afirmação de que o excesso de burocracia estimula a corrupção (IPSOS, 2017, p. 02).

É urgente, assim, alcançar um meio termo, um ponto de equilíbrio: combater com vigor a corrupção, mas sem onerar sobremodo a sociedade. Daí a meta 16.5 dos ODS propugnar a "redução" da corrupção, redução essa a ser balanceada com os custos sociais das medidas implementadas, no lugar de instar os Estadosmembros da ONU a "eliminarem" a corrupção, o que além de inviável poderia gerar excessos não desejados.

O outro aspecto que convém ser salientado corresponde ao alcance da meta, que não se restringe à corrupção pública, mas abarca também à corrupção privada, na medida em que expressamente se busca reduzir a corrupção e o suborno "em todas as suas formas".

No Brasil, a corrupção privada ainda não possui um tratamento adequado, inclusive na legislação criminal, inexistindo o crime de corrupção privada, contrariamente ao que ocorre com os crimes de corrupção pública ativa e passiva.

A Convenção de Mérida, porém, conclama, no artigo 21, o Brasil e os demais Estados signatários a promulgarem leis que qualifiquem como delito a corrupção privada, ou, na diç̧ão do tratado, o suborno no setor privado. Ainda, exorta, no artigo 22, os Estados signatários a também criminalizarem a malversação e o peculato de bens no setor privado. Como fruto inicial dessa obrigação convencional, foi elaborado no seio da Estratégia Nacional de Combate à Corrupção e à Lavagem de Dinheiro (ENCCLA, 2018), dentro da Ação 05/2018, um anteprojeto de lei que, acrescentando o art. $4^{\circ}$-A à Lei no 8.137 , de 1990, tipificará o crime de corrupção privada.

Além do tratamento concedido ao combate à corrupção pela AGENDA 2030 da ONU, também em nível regional houve avanços recentes na temática, os quais serão narrados na seção seguinte, a partir do emblemático caso Ramírez Escobar y Otros vs. Guatemala, julgado pela Corte Interamericana de Direitos Humanos. 


\section{RAMÍREZ ESCOBAR Y OTROS VS. GUATEMALA: UM CASO DE CORRUPÇÃO E VIOLAÇÕES DE DIREITOS HUMANOS NA CORTE INTERAMERICANA}

No ano de 2018, a Corte Interamericana teve a oportunidade, ao que se saiba pela primeira vez, de relacionar diretamente um caso emblemático de violação de direitos humanos à corrupção de agentes públicos. Esse é o caso que vamos abordar ligeiramente.

A Corte Interamericana de Direitos Humanos, instituição judicial autônoma, é um dos órgãos da Convenção Americana de Direitos Humanos, de cujo artigo 33 decorre a sua criação, não se inserindo, ao contrário da Comissão Interamericana de Direitos Humanos, na estrutura da Organização dos Estados Americanos (RAMOS, 2012a, p. 221).

Composta por sete juízes indicados pelos Estados-partes da Convenção Americana de Direitos Humanos, os quais são escolhidos em sessão da Assembleia Geral da Organização dos Estados Americanos, a Corte Interamericana de Direitos Humanos está sediada em San José, na Costa Rica. Somente detêm legitimidade ativa para provocar a jurisdição da Corte os Estados-parte e a Comissão Interamericana de Direitos Humanos.

Segundo dados da própria Corte Interamericana, até o final de dezembro de 2017 foram resolvidos duzentos e trinta e sete casos pelo tribunal (CORTE IDH, 2018b, p. 65). O Brasil já foi condenado em diversos casos pela Corte Interamericana de Direitos Humanos, dentre os quais se destacam os casos Gomes Lund e outros (Guerrilha do Araguaia), Favela Nova Brasília, Trabalhadores da Fazenda Brasil Verde, Povo Indígena Xucuru, Herzog e outros etc.

Por se tratar de uma Corte internacional capaz de realizar a responsabilização internacional dos Estados-membros que aceitam sua jurisdição a partir da aplicação não só da Convenção 
Interamericana de Direitos Humanos, como também de outros tratados relacionados à proteção dos direitos humanos, a Corte Interamericana de Direitos Humanos vêm desempenhando um papel relevante na defesa de direitos fundamentais de liberdade, a exemplo dos direitos fundamentais das pessoas que se encontram em situação de privação de liberdade pelo cometimento de algum crime (FEITOSA; PESSOA, 2019, p. 14). No entanto, outro olhar sobre violações de direitos humanos e suas interconexões com direitos fundamentais de terceira dimensão vem ganhando força no debate judicial da Corte Interamericana, e é nessa nova toada que a corrupção passou a ser considerada uma espécie de violação a direitos humanos, como se explica adiante.

Em 9 de março de 2018, a Corte Interamericana de Direitos Humanos prolatou uma sentença emblemática. Trata-se do caso Ramírez Escobar y Otros Vs. Guatemala, submetido à jurisdição da Corte pela Comissão Interamericana de Direitos Humanos em 12 de fevereiro de 2016.

O caso concreto diz respeito à adoção internacional dos irmãos guatemaltecos Osmín e J.R. Ramírez, respectivamente com sete anos e um ano de idade, a qual foi marcada de ilegalidades processuais e de direito material. Os irmãos Ramírez foram retirados de suas famílias e internados numa casa de acolhimento. Em seguida, foram declarados em situação de abandono e, após, adotados por duas famílias estadunidenses distintas, sem observância da própria legislação local sobre direito de família e de adoção.

A Corte Interamericana de Direitos Humanos reconheceu a violação de diversos direitos consagrados na Convenção Americana de Direitos Humanos, desde o dever estatal de investigar ao dever estatal de tipificar delitos (no caso, o tráfico internacional de pessoas para fins de adoção), passando pelo direito à liberdade pessoal e à integridade pessoal das crianças vitimadas. $\mathrm{O}$ grande destaque, entretanto, foi o vigoroso ataque à corrupção enquanto potencial violadora de direitos humanos, registrando a Corte que o propósito dos agentes públicos 
envolvidos no processo sobejamente ilegal de adoção internacional dos irmãos guatemaltecos Osmín e J.R. Ramírez foi de obter o próprio enriquecimento, em detrimento da observância dos direitos das crianças.

Pela importância histórica, é bastante oportuno transcrever três dos parágrafos da sentença do caso Ramírez Escobar e outros Vs. Guatemala, nos quais a Corte examina os efeitos nocivos da corrupção nos direitos humanos em geral e em particular em face das crianças adotadas internacionalmente na Guatemala ao arrepio da lei (CORTE IDH, 2018a):

240. Ademais, a Corte reitera que essas adoções se deram no marco de um contexto no qual a fragilidade institucional e a flexibilidade normativa facilitou a formação de redes e estruturas de crime organizado dedicados ao negócio de ações irregulares. Como foi ressaltado por vários peritos perante esta Corte e pela CICIG, na Guatemala as ações não atendiam ao interesse superior da criança, mas sim os abrigos, notários e autoridades judiciais respondiam em grande medida a interesse econômicos. Ademais, este Tribunal destaca como estas redes de adoções ilegais dentro das estruturas do Estado não só se aproveitaram das fragilidades institucionais e legais do Estado guatemalteco, como também da situação de vulnerabilidade das mães e família vivendo em situação de pobreza na Guatemala.

241. A respeito, este Tribunal destaca as consequências negativas da corrupção e os obstáculos que representa para o gozo e desfrute efetivo dos direitos humanos, assim como o fato de que a corrupção de autoridades estatais ou de particulares prestadores de serviços públicos afeta de uma maneira particular aos grupos vulneráveis. Ademais, a corrupção não só afeta os particulares individualmente afetados, mas repercute negativamente em toda a sociedade, na medida em que "quebra a confiança que a população tem no governo e, com o tempo, na ordem democrática e no estado de direito". Nesse sentido, a Convenção Americana contra a Corrupção estabelece no seu preâmbulo que "a democracia representativa, condição indispensável para a estabilidade, a paz e o desenvolvimento da região, por sua natureza, exige combater toda forma de corrupção no exercício das funções públicas, assim como os atos de corrupção especificamente relacionados a esse exercício".

242. A Corte recorda que os Estados devem adotar medidas para prevenir, sancionar e erradicar eficaz e eficientemente a corrupção. Não obstante, como se mencionou previamente, o sistema de proteção da infância e os mecanismos de adoção vigentes na Guatemala na época dos fatos, longe de cumprir estas obrigações, proporcionaram espaços para que tivesse lugar e permitiram a formação e manutenção de redes de adoções ilegais na Guatemala. $\mathrm{O}$ caso presente poderia refletir uma 
materialização desse contexto. A Corte destaca que as adoções internacionais se deram dentro de um quadro de corrupção, no qual um conjunto de atores e instituições públicos e privados operaram sob o manto da proteção do interesse superior do menor, porém com o real propósito de obter o seu próprio enriquecimento. (tradução nossa) 7

A decisão da Corte Interamericana foi lapidar ao deixar claro como a corrupção pode prejudicar diretamente direitos humanos (no caso concreto, vários direitos dos irmãos Ramírez), mas por si só repercute negativamente na sociedade ao abalar a confiança da sociedade na democracia e no Estado de Direito, como expusemos na seção 3 deste artigo.

7 No original: 240. Además, la Corte reitera que estas adopciones se dieron en el marco de un contexto en el cual la debilidad institucional y la flexibilidad normativa facilitó la formación de redes y estructuras de delincuencia organizada dedicadas al negocio de las adopciones irregulares (supra párrs. 61 a 71 y 145). Como fue resaltado por varios peritos ante esta Corte y por la CICIG, en Guatemala las adopciones no respondían al interés superior del niño, sino que casas de abrigo, notarios y autoridades judiciales respondían en gran medida a intereses económicos. Además, este Tribunal destaca cómo estas redes de adopciones ilegales engranadas dentro de las estructuras del Estado no solo se aprovecharon de las debilidades institucionales y legales del Estado guatemalteco sino también de la situación de vulnerabilidad de las madres y familias viviendo en situación de pobreza en Guatemala (supra párrs. 61, 68 e infra párr. 282). 241. Al respecto, este Tribunal destaca las consecuencias negativas de la corrupción y los obstáculos que representa para el goce y disfrute efectivo de los derechos humanos, así como el hecho de que la corrupción de autoridades estatales o prestadores privados de servicios públicos afecta de una manera particular a grupos vulnerables. Además, la corrupción no solo afecta los derechos de los particulares individualmente afectados, sino que repercute negativamente en toda la sociedad, en la medida en que "se resquebraja la confianza de la población en el gobierno y, con el tiempo, en el orden democrático y el estado de derecho". En este sentido, la Convención Interamericana contra la Corrupción establece en su preámbulo que "la democracia representativa, condición indispensable para la estabilidad, la paz y el desarrollo de la región, por su naturaleza, exige combatir toda forma de corrupción en el ejercicio de las funciones públicas, así como los actos de corrupción específicamente vinculados con tal ejercicio". 242. La Corte recuerda que los Estados deben adoptar las medidas para prevenir, sancionar y erradicar eficaz y eficientemente la corrupción. No obstante, como se mencionó previamente, el sistema de protección de la niñez y los mecanismos de adopción vigentes en Guatemala en la época de los hechos, lejos de cumplir estas obligaciones, proporcionaron espacios para que tuviera lugar y permitieron la formación y mantenimiento de las redes de adopciones ilegales en Guatemala. El presente caso podría reflejar una materialización de este contexto. La Corte destaca que las adopciones internacionales se dieron dentro de un marco de corrupción, en el que un conjunto de actores e instituciones públicos y privados operaban bajo el manto de la protección del interés superior del niño, pero con el real propósito de obtener su propio enriquecimiento. En este sentido, la maquinaria que se montó y toleró alrededor de las adopciones ilegales, la cual afectaba de manera particular a sectores pobres, tuvo un fuerte impacto negativo en el disfrute de los derechos humanos de los niños y sus padres biológicos. 
A partir do precedente Ramírez Escobar y otros vs. Guatemala, é de se esperar que a Corte "aprofunde a sua compreensão sobre a corrupção sistêmica (grand corruption) como violadora dos direitos à educação, à saúde, à segurança pública, ao saneamento básico, ao meio ambiente sustentável e ao [...] direito do povo a governos honestos" (ARAS, 2018).

Que a Corte Interamericana de Direitos Humanos, que criou farta jurisprudência sobre os casos de desaparecimento forçado que inundaram o continente latino-americano em décadas passadas, avance cada vez mais para contribuir para a redução da corrupção, que assola, atualmente, à parcela do continente americano com raízes ibéricas. A promoção dos direitos humanos só tem a ganhar com esse indispensável apoio.

\section{CONCLUSÃO}

Ao longo do artigo, procuramos demonstrar que os direitos humanos não são um dado, mas um construído, fruto de lutas históricas, a partir das quais vêm se ressignificando dia após dia. Saber se num dado contexto houve ou há violações de direitos humanos, dessa forma, exige levar em consideração, num primeiro momento, o que se entende por direitos humanos, a partir da leitura da reconstrução contínua deles.

A corrupção, quando não se trata de um ato isolado, mas está disseminada no meio social, pode ser encarada como uma maneira por qual violações de direitos humanos se manifestam, seja pelo fato de ela afetar diretamente direitos civis, sociais e difusos, seja pelo fato de ela por si só abalar a confiança que a população tem no governo e, consequentemente, a credibilidade do Estado Democrático de Direito, que é posto em xeque com os desvios a que os atos corruptos correspondem.

Nessa linha, os órgãos internacionais estão pouco a pouco 
Caso Ramírez Escobar Y Otros vs. Guatemala: Um Novo Olhar Da Corte...

ampliando a concepção do que se compreende por violação de direitos humanos para inserir em tal categoria a corrupção. Exemplo notável dessa consciência foi a inclusão de uma meta específica sobre a redução da corrupção dentro dos Objetivos de Desenvolvimento Sustentável, no seio da Agenda 2030. Esse reconhecimento é importante porque, além de fazer voltar a atenção dos Estados e entes internacionais à problemática da corrupção - cujos malefícios não devem ser subestimados -, permite colocar a serviço do seu enfrentamento os mecanismos globais e regionais de apuração das violações de direitos humanos.

Essa tendência foi robustecida recentemente com a decisão da Corte Interamericana de Direitos Humanos no caso Ramírez Escobar e outros Vs. Guatemala, no qual a Corte pela primeira vez se deteve com razoável profundidade sobre a relação entre corrupção e violações de direitos humanos e recriminou de forma contundente os atos de corrupção e os males por eles causados.

Portanto, podemos afirmar que a prática de atos de corrupção em sentido amplo viola sim direitos humanos, merecendo rigoroso combate. Essa consciência, aliada ao reforço da atuação dos órgãos internacionais de promoção dos direitos humanos na luta contra a corrupção, traz a esperança de um futuro mais justo e ético.

Data de Submissão: 03/03/2019

Data de Aprovação: 14/04/2020

Processo de Avaliação: double blind peer review

Editor Geral: Jailton Macena de Araújo

Editor de Área: Gustavo Barbosa de Mesquita Batista

Assistente Editorial: Jaqueline Rosário Santana 


\section{REFERÊNCIAS}

\section{AGENDA 2030. Os 17 Objetivos de Desenvolvimento}

Sustentável. Disponível

em:http://www.agenda2030.com.br/ods/16/. Acesso em: 28 nov. 2018.

ANJOS, Lislaine dos. Desvios em obras de saneamento prejudicaram 800 mil pessoas, diz PF. G1, 19 nov. 2015. Disponível em: http://g1.globo.com/mato-grosso/noticia/2015/11/desvios-emobras-de-saneamento-prejudicaram-80o-mil-pessoas-diz-pf.html. Acesso em: 2 dez. 2018.

ARAS, Vladimir. Corrupção e direitos humanos no sistema interamericano. Blog do Vlad, 22 nov. 2018. Disponível em: $<$ https://vladimiraras.blog/2018/11/22/corrupcao-e-direitoshumanos-no-sistema-interamericano/>. Acesso em: 23 nov. 2018.

BACIO-TERRACINO, Julio. Corruption as a Violation of Human Rights. International Council on Human Rights Policy. Jan 2008. Disponível em:https://ssrn.com/abstract $=1107918$. Acesso em: 2 dez. 2018.

BIELEFELDT, Heiner. Filosofia dos direitos humanos: fundamentos de um ethos da liberdade universal. São Leopoldo: UNISINOS, 2000.

BOBBIO, Noberto. A era dos direitos. Rio de Janeiro: Elsevier, 2004.

BONAVIDES, Paulo. Curso de direito constitucional. 25 ed., atual. São Paulo: Malheiros, 2010.

BRAGON, Ranier. Câmara desfigura pacote anticorrupção do Ministério Público. Folha de São Paulo, 30 nov. 2016. Disponível em:https://www1.folha.uol.com.br/poder/2016/11/1836979-namadrugada-camara-fulmina-pacote-anticorrupcao-do-ministeriopublico.shtml. Acesso em: 25 abr. 2019.

BRASIL. Decreto no 4.410, de 7 de outubro de 2002. Promulga a Convenção Interamericana contra a Corrupção, de 29 de março de 1996, com reserva para o art. XI, parágrafo $1^{\circ}$, inciso "c". Disponível em:

http://www.planalto.gov.br/ccivil_03/decreto/2002/D4410.htm. Acesso em: 3 dez 2018.

CARVALHO, Paulo Roberto Galvão de. Legislação anticorrupção no mundo: análise comparativa entre a Lei Anticorrupção brasileira, o Foreign Corrupt Practices Act norte-americano e o Bribery Act do 
Caso Ramírez Escobar Y Otros vs. Guatemala: Um Novo Olhar Da Corte...

Reino Unido. In: Lei Anticorrupção. QUEIROZ, Ronaldo Pinheiro de; SOUZA, Jorge Munhós (org.). Salvador: Juspodivm, 2015. p. 3562.

COMPARATO, Fábio Konder. A afirmação histórica dos

direitos humanos. 4 ed. rev. e atual. São Paulo: Saraiva, 2005.

CORTE INTERAMERICANA DE DIREITOS HUMANOS (CORTE IDH). Caso Ramírez Escobar y Otros Vs. Guatemala.

Sentencia De 9 De Marzo De 2018 (Fondo, Reparaciones y Costas).

San José: 2018. Disponível em:

http://www.corteidh.or.cr/docs/casos/articulos/seriec_351_esp.pdf. Acesso em: 3 dez. 2018.

CORTE INTERAMERICANA DE DIREITOS HUMANOS (CORTE IDH). Relatório anual 2017 da Corte Interamericana de Direitos Humanos. San José: 2018. Disponível em:

http://www.corteidh.or.cr/tablas/informe2017/portugues.pdf. Acesso em: 3 dez. 2018.

ESTRATÉGIA NACIONAL DE COMBATE À CORRUPÇÃO E À LAVAGEM DE DINHEIRO (ENCCLA). Ação o5/2018, 2018. Disponível em:http://enccla.camara.leg.br/acoes/copy_of_ENCCLA2018Ao5Ti pificaopenaldecorrupoprivada.pdf. Acesso em: 4 dez. 2018.

FEITOSA, Gustavo Raposo Pereira; PESSOA, Manoela Fleck de Paula. Corte Interamericana De Direitos Humanos e o encarceramento em massa: ama análise dos casos do Complexo Penitenciário de Pedrinhas e Curado. Prim@ Facie, Vol 18, número 39, p. 114-147, 2019.

FERREIRA FILHO, Manoel Gonçalves. Direitos humanos fundamentais. 13 ed. São Paulo: Saraiva, 2011.

FIGUEIREDO, Janaína. Latinobarômetro: Corrupção aparece pela $1^{\mathrm{a}}$ vez como principal preocupação para Brasil, diz pesquisa. O Globo, 27 out. 2017. Disponível em:https://oglobo.globo.com/brasil/latinobarometro-corrupcaoaparece-pela-1-vez-como-principal-preocupacao-para-brasil-dizpesquisa-21999964. Acesso em: 10 nov. 2018.

GENERAL ASSEMBLY. Resolution adopted by the General Assembly on 25 September 2015. Disponível

em:http://www.un.org/ga/search/view_doc.asp?symbol=A/RES/70 /1\&Lang=E. Acesso em: 29 nov. 2018.

GRANDIN, Felipe. Obras da Odebrecht foram superfaturadas em mais de R $\$ 3$ bilhões no RJ. G1, 24 jun. 2017. Disponível em:https://g1.globo.com/rio-de-janeiro/noticia/obras-da-odebrechtforam-superfaturadas-em-mais-de-r-3-bilhoes-no-rj.ghtml. Acesso 
em: 2 dez. 2018.

GUIMARÃES, Juarez. Interesse público. In: Corrupção: ensaios e críticas. BIGNOTTO, Newton; GUIMARÃES, Juarez; STARLING, Heloisa Murgel (org.). Belo Horizonte: Editora UFMG, 2012. p. 147151.

HOLMES, Leslie. Corruption: a very short introduction. Oxford: Oxford University Press, 2015.

INSTITUTO BRASILEIRO DE CIÊNCIAS CRIMINAIS (IBCCRIM). Editorial. Todos contra a corrupção. Boletim. p. 01. São Paulo, ano 23, $\mathrm{n}^{0}$ 277, Dez. 2015.

INSTITUTO TRATA BRASIL. Ranking do saneamento Instituto Trata Brasil. Disponível em:

http://www.tratabrasil.org.br/images/estudos/itb/ranking2018/realatorio-completo.pdf. Acesso em: 20 nov. 2018.

IPSOS. Pesquisa Pulso Brasil FIESP/CIESP. Burocracia. Mar. 2017. Disponível em: https://www.fiesp.com.br/indices-pesquisas-epublicacoes/pulsos/attachment/pulso_burocracia_versao-3/.Acesso em: 5 dez. 2018.

KLITGAARD, Robert. A corrupção sob controle. Rio de Janeiro: Jorge Zahar, 1994.

KOKELE-KALE, Ndiva. The International Lawyer, Vol. $34, \mathrm{~N}^{0} 1$, p. 149-178, 2000. Disponível em:

https://scholar.smu.edu/cgi/viewcontent.cgi?article=1957\&context= til. Acesso em: 8 abr. 2020.

MENDONÇA, Ricardo. Pela $1^{\mathrm{a}}$ vez, corrupção é vista como maior problema do país, diz Datafolha. Folha de São Paulo, 29 nov. 2015. Disponível em:

https://www1.folha.uol.com.br/poder/2015/11/1712475-pela-1-vezcorrupcao-e-vista-como-maior-problema-do-pais.shtml. Acesso em: 10 nov. 2018.

MUNGIU-PIPPIDI, Alina. The quest for good governance: how societes develop control of corruption. New York: Cambridge University Press, 2015.

NATIONAL ARCHIVES. The Virginia Declaration of Rights. America's Founding Documents, 29 set. 2016. Disponível em: https://www.archives.gov/founding-docs/virginia-declaration-ofrights. Acesso em: 10 nov. 2018.

PALIFKA, Bonnie K.; ROSE-ACKERMAN, Susan. Corruption and governement: causes, consequences, and reform. 2 ed. New York: Cambridge University Press, 2015. 
Caso Ramírez Escobar Y Otros vs. Guatemala: Um Novo Olhar Da Corte...

PETERS, Anne. Corruption and human rigths. Basel: Basel Institute of Governance, 2015.

PIMENTEL FILHO, André. (Uma) teoria da

corrupção: corrupção, estado de direito e direitos humanos. Rio de Janeiro: Lumen Juris, 2015.

RAMOS, André de Carvalho. Processo internacional de direitos humanos. 2 ed. São Paulo: Saraiva, 2012a.

RAMOS, André de Carvalho. Teoria geral dos direitos humanos na ordem internacional. 2 ed. São Paulo: Saraiva, 2012b.

SAMPAIO, José Adércio Leite. Direitos fundamentais: retórica e historicidade. 2 ed. Belo Horizonte: Del Rey, 2010.

SOARES, Danyele. Fiesp avalia perda anual de R $\$ 130$ bi em corrupção; valor pode ser ainda maior. Radioagência Nacional, 8 dez. 2017. Disponível em:

http://radioagencianacional.ebc.com.br/politica/audio/201712/fiesp-avalia-perda-anual-de-r-130-bi-em-corrupcao-valor-podeser-ainda-maior. Acesso em: 28 nov. 2018.

SÓFOCLES. A trilogia tebana; tradução do grego, introdução e notas de Mário da Gama Kury. 10 ed. Rio de Janeiro: Jorge Zahar Ed., 2002.

SOUZA, Josias de. Corrupção incide mais sobre educação e saúde. Blog do Josias - Uol, 31 jul. 2016. Disponível em: https://josiasdesouza.blogosfera.uol.com.br/2016/o7/31/corrupcaoincide-mais-sobre-educacao-e-saude/. Acesso em: 2 dez. 2018.

TRANSPARÊNCIA INTERNACIONAL. Integridade e empresas no Brasil. Disponível em:

https://transparenciainternacional.org.br/assets/files/conhecimento /relatorio-executivo.pdf. Acesso em: 2 dez. 2018.

TRIBUNAL DE CONTAS DA UNIÃO (TCU). Auditoria

operacional sobre obras paralisadas. Brasília: 2019. Disponível em: https://portal.tcu.gov.br/biblioteca-digital/auditoria-

operacional-sobre-obras-paralisadas.htm. Acesso em: 14 abr. 2020.

UNITED NATIONS OFFICE OF THE HIGH COMMISSIONER FOR HUMAN RIGHTS (OHCHR). United Nations Conference on Anti-Corruption Measures, Good Governance and Human Rights. Warsaw, 9 nov. 2006. Disponível em: http://www2.ohchr.org/english/issues/development/governance/do cs/background_note.doc. Acesso em: 30 nov. 2018.

UNITED NATIONS OFFICE ON DRUGS AND CRIME (UNODC).

Signature and Ratification Status. Disponível em: 
http://www.unodc.org/unodc/en/corruption/ratificationstatus.html. Acesso em: 3 dez. 2018.

VERÍSSIMO, Carla. Compliance: incentivo de adoção de medidas anticorrupção. São Paulo: Saraiva, 2017. 


\title{
Ramírez Escobar y Otros Vs. Guatemala Case: a new approach about human rights by the Inter-American Court of Human Rights
}

\author{
Flávio Pereira da Costa Matias
}

Julio Cesar de Aguiar

\begin{abstract}
This article aims to discuss the new approach by the Inter-American Court of Human Rights from the relation between human rights and corruption, starting from the historical construction of human rights to examine if corruption can be considered a kind of breach of human rights, and, if so, under what assumptions. It's demonstrated the way in which international law deals with corruption, both regionally and globally, usually from the perspective of the fight against corruption. Particular attention is given to the treatment accorded by the United Nations to the reduction of corruption within the scope of Sustainable Development Goals under Agenda 2030, and to recent decision of the InterAmerican Court of Human Rights in Ramírez Escobar y Otros Vs. Guatemala case, which has explicitly addressed the relationship between corruption and human rights violation. It is concluded that corruption is a form of violation of human rights. The method used for the article was the bibliographic research, of exploratory nature, using diverse human rights texts and international treaties, and the jurisprudential research of the Inter-American Court of Human Rights.
\end{abstract}

Keywords: Corruption. Human Rights. Inter-American Court of Human Rights. 